\title{
UV EXPOSURE UNIT FOR PCB PROTOTYPING
}

\author{
KORIC, A[Ifred]; ZENZEROVIC, P[aolo] \& VRANKIC, M[iroslav]
}

\begin{abstract}
This paper presents a solution for an electronic printed circuit board (PCB) production device based on a photolithographic production approach. The motivation for the development of such a device form scratch is to make a low cost device suitable for educational facilities. The device is completely automated to simplify its usage. All technical solutions and other assumptions related to this project are confirmed by computer simulations and complete hardware implementation. The article also describes and compares available solutions in terms of light source usage, working area and price.
\end{abstract}

Keywords: $P C B$, photolithography, exposure unit, engineering education, $U V$ exposure

\section{INTRODUCTION}

Despite the fast development of the electronics industry, the basic ideas behind the PCB production process haven't changed a lot during the past. The photolithographic process of PCB production is the most commonly used method both in the professional and amateur world. Hence, the PCB production process using photolithography is used both for large quantity PCB production, for small series production and prototyping.

In the professional usage there is a need to produce PCBs quickly and efficiently in order to shorten the research and development phase of product design thus reducing the time from prototype to market. On the other hand in the amateur world of PCB production, as well as in the educational facilities, such as universities, high schools, technical education centers etc., the main need is to produce prototypes and small series production quickly and cheaply. In this article an open software and open hardware device is presented which meets the criteria that is mentioned above.

\section{PHOTOLITHOGRAPHY}

Photolithography (also called "optical lithography" or "UV lithography") is a process used in fabrication to selectively remove parts of a thin film or the bulk of a substrate. It uses light to transfer a geometric pattern from a photomask to a light-sensitive chemical "photoresist", or simply "resist," on the substrate [1].

A high precision version of this method is used to make printed circuit boards. It is used because it can create really small patterns and it gives the possibility of exactly controlling the shape and size of the objects it creates. Its main disadvantages are that it is not very effective at creating shapes that are not flat and it requires clean operating conditions [2].
The procedure of PCB photolithography combines several steps in sequence and is briefly described below. The steps are graphically represented in Figure 2.

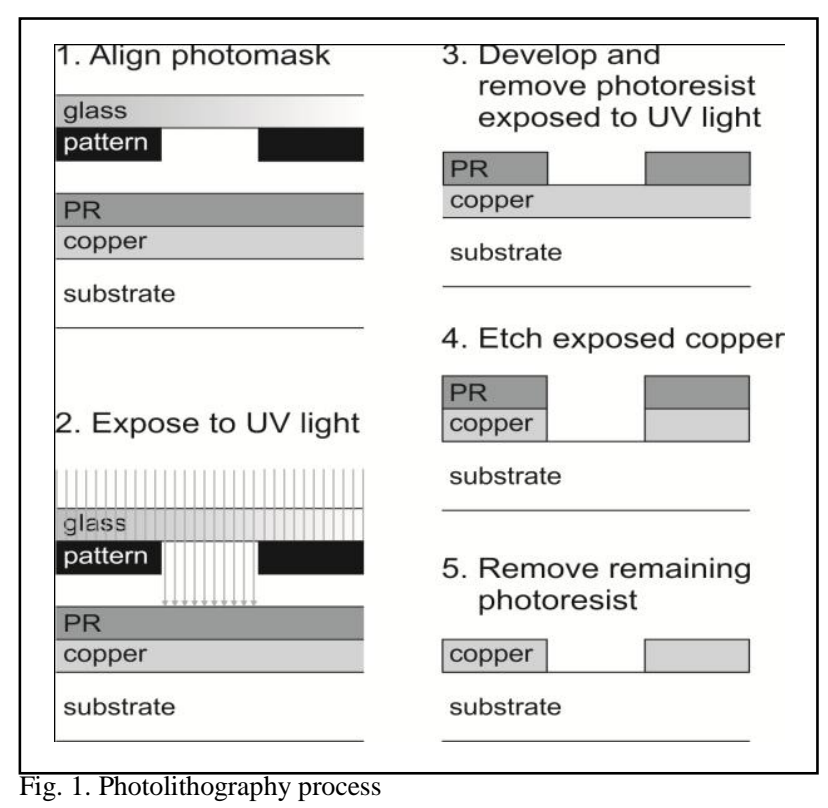

\subsection{Cleaning and photoresist application}

There are boards that are already covered by photoresist (also called "presensitized copper clad boards") and ordinary copper clad boards that don't contain photoresist. Presensitized copper clad boards are more expensive but they give better results. So, if one chooses a plain copper clad board, one should first remove any surface contaminations if they are present on the board. Then a positive photoresist layer should be applied using photoresist spray.

\subsection{Exposure}

The photoresist is exposed to a pattern of intense light. The exposure to light causes a chemical change that allows some of the photoresist to be removed by a special solution, called "developer" by analogy with photographic developer. Positive photoresist, the most common type, becomes soluble in the developer when exposed; with negative photoresist, unexposed regions are soluble in the developer. The spectral sensitivity for the photoresist layers usually lies in the wave length range from 300 to $450 \mathrm{~nm}$.

\subsection{Developing}

After exposing, the board is immersed in a developer that removes exposed photoresist. The developer is a solution of sodium hydroxide $(\mathrm{NaOH})$ in water. 


\subsection{Etching}

In etching, a liquid chemical agent removes the uppermost layer of the substrate in the areas that are not protected by photoresist. Etching solution is a solution of iron trichloride in water or can be made of certain ratios of hydrochloric acid and hydrogen peroxide.

\section{AVAILABLE SOLUTIONS}

Most of commercial exposure systems use UV lamps while metal-halide lamps are more or less applied in the industry. Recent solutions include UV LED panels.

\subsection{Exposure systems with UV tubes}

Fluorescent lamps require a ballast for start and that's the main problem because ballasts are often bulky, expensive and difficult to find. UV tubes have a lifetime of 5000-15000 hours which is less than lifetime of metalhalide lamps, but their light spectrum is concentrated in the range of the UV light [3]. This type of lighting is more frequently used in smaller exposure systems for commercial purpose.

\subsection{Exposure systems with Metal-halide lamps}

Metal-halide lamps are used in large exposure systems intended for industrial production. They have a slightly longer life than fluorescent lamps (15000-20000 hours) but their light spectrum is widespread. Depending on the version, they may or may not require special fixtures with ballasts.

\subsection{Exposure systems with UV LED panel}

LED technology has many advantages over other light sources like long operational life (about 100000 hours), low power consumption, they don't require any type of fixture etc. The PCB industry possibly does not use LED panels because of the need for larger work areas, but they are suitable for installation in smaller systems.

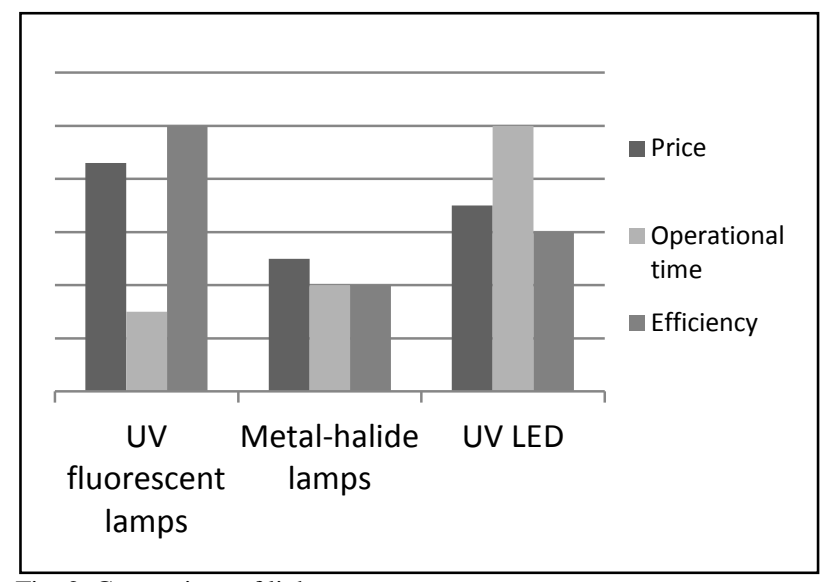

Fig. 2. Comparison of light sources

\section{IMPLEMENTED SOLUTION}

Implemented UV exposure unit for PCB production has the following specifications:

- working area: $21 \times 26 \mathrm{~cm}$

- UV output: 6 x 8 watt

- dimensions: 29 x 43 x 9,5 cm

- weight: $4,3 \mathrm{~kg}$

- digital timer with LCD (0-10 min)
Operation of the unit is simple. The time of exposure in minutes and seconds (step: 1 for minutes, 5 for seconds) has to be set, then the number of lights used to expose the board is chosen (half/full, depending on the size of the board, 3 or 6 lamps are used). The final step is to insert the appropriate board with the pattern, close the lid and press the enter button. The buzzer sounds for a 500 milliseconds and the exposure cycle begins. During exposure, the timer counts down and the red LED indicator is blinking. The system has an option to terminate the process if the enter button is pressed during the exposure. Once the cycle is complete, the display returns to the original setting. When the exposure is complete the LED illuminates, and a buzzer sounds three times, each time for 250 milliseconds.

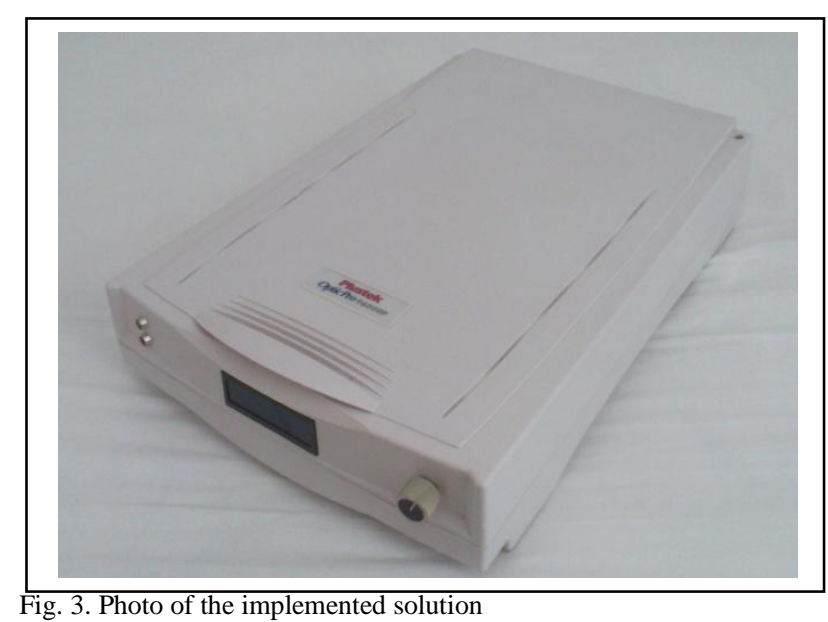

The unit includes the following sections: UV output unit, electronic timer controller, power supply unit and a housing. All of the sections will be described in the following chapters.

\subsection{UV output unit}

This section contains six Phillips Actinic BL T5 lamps. With an optimized performance to attract most insects, Actinic BL T5 lamps are the ideal choice for electronic insect killer systems. They are also suitable for photopolymerization and reprographic processes [4].

General characteristics are:

- Main Application: Reprography

- Useful Life: $5000 \mathrm{hr}$

- Lamp Wattage: $8 \mathrm{~W}$

- Overall Length: 302.5 (max) mm

- Diameter: $16(\max ) \mathrm{mm}$

The spectral sensitivity of Actinic BL T5 lamp is almost entirely located in the wave length range 340 to $410 \mathrm{~nm}$ while only a small fraction exists in the wave lengths near $420 \mathrm{~nm}$. So, the radiation produced by this type of lamp belongs to the longwave - UVA radiation which is harmful to the eyes. For this purpose the device has a plastic lid which must be closed during the exposure. 


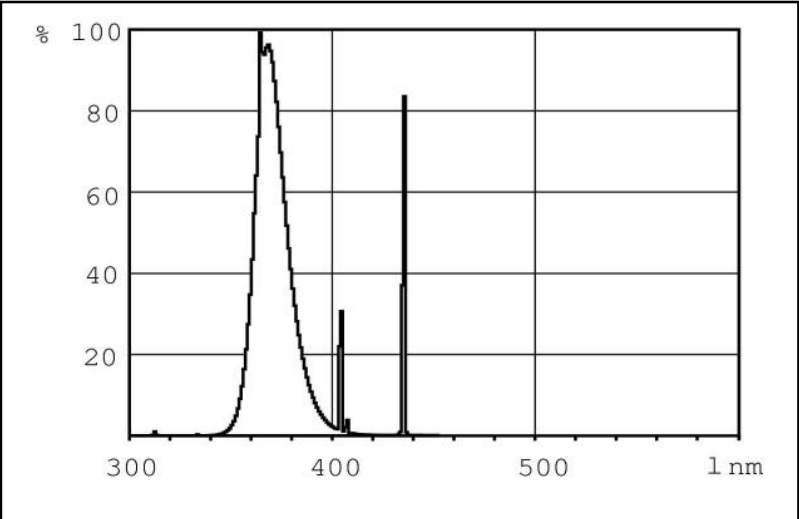

Fig. 4. Phillips Actinic BL T5 light spectrum

In addition to the lamps, this section includes six pieces of T5 Fluorescent Light Fixture (Opple MX313Y8Z). With affordable price and compact design that fits even the narrowest space, T5 Fluorescent Light Fixture has patent curved profile with optimal optic effect that enables this light fixture to capture normally wasted light, thereby increasing output by $30 \%$ [5].

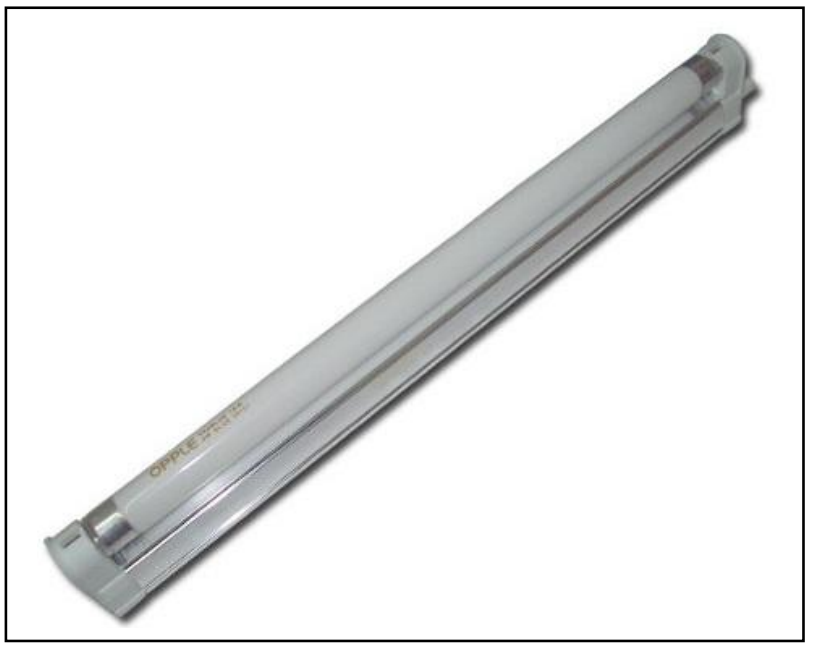

Fig. 5. T5 Fluorescent Light Fixture

\subsection{Electronic timer controller}

The electronic timer controller (also called "digital timer") allows the user to adjust the exposure time and lights operation. It can be subdivided into the following sections: system controller (microcontroller), control relay circuit, LCD display, control pushbuttons, LED indicators and buzzer.

Implementation of the timer is performed on the PCB and includes all required elements (basic microcontroller circuit, pull-down resistors for pushbuttons, two relay circuits, buzzer, connectors etc.). Peripheral units, such as LCD, pushbuttons and LED indicators as well as lamps section terminals are connected to compatible PCB connectors and are located on the housing. Wiring and installation are performed in a way that the housing of the device can be easily opened especially for the purpose of changing lamps or in case of device failure.

\subsection{Power supply unit}

This unit can be functionally divided into two parts: power supply for lamps and power supply for timer.

T5 Fluorescent light fixtures are powered directly from the mains $(220-240 \mathrm{~V} \mathrm{AC}, 50 / 60 \mathrm{~Hz})$ and controlled by electronic timer controller. Therefore the power supply for the lamps is derived through the relay circuit on the $\mathrm{PCB}$

The entire electronic timer controller circuit is powered from a voltage regulator which provides +5 volts at its output. It is a simple DC stabilized power supply which supplies all the elements of the timer: microcontroller, relay control circuit, LCD unit, LED indicators and a buzzer.

Total power consumption of the device is approximately $50 \mathrm{~W}(230 \mathrm{~V})$. The lamps consume $48 \mathrm{~W}$ while the electronic timer controller consumes less than 2 $\mathrm{W}$. The device also has a fuse for security purposes.

\subsection{Housing}

Due to the simplicity of implementation, the plastic housing of the old scanner is used. The reason for choosing this enclosure is to reuse electronic waste and promote the recycling.

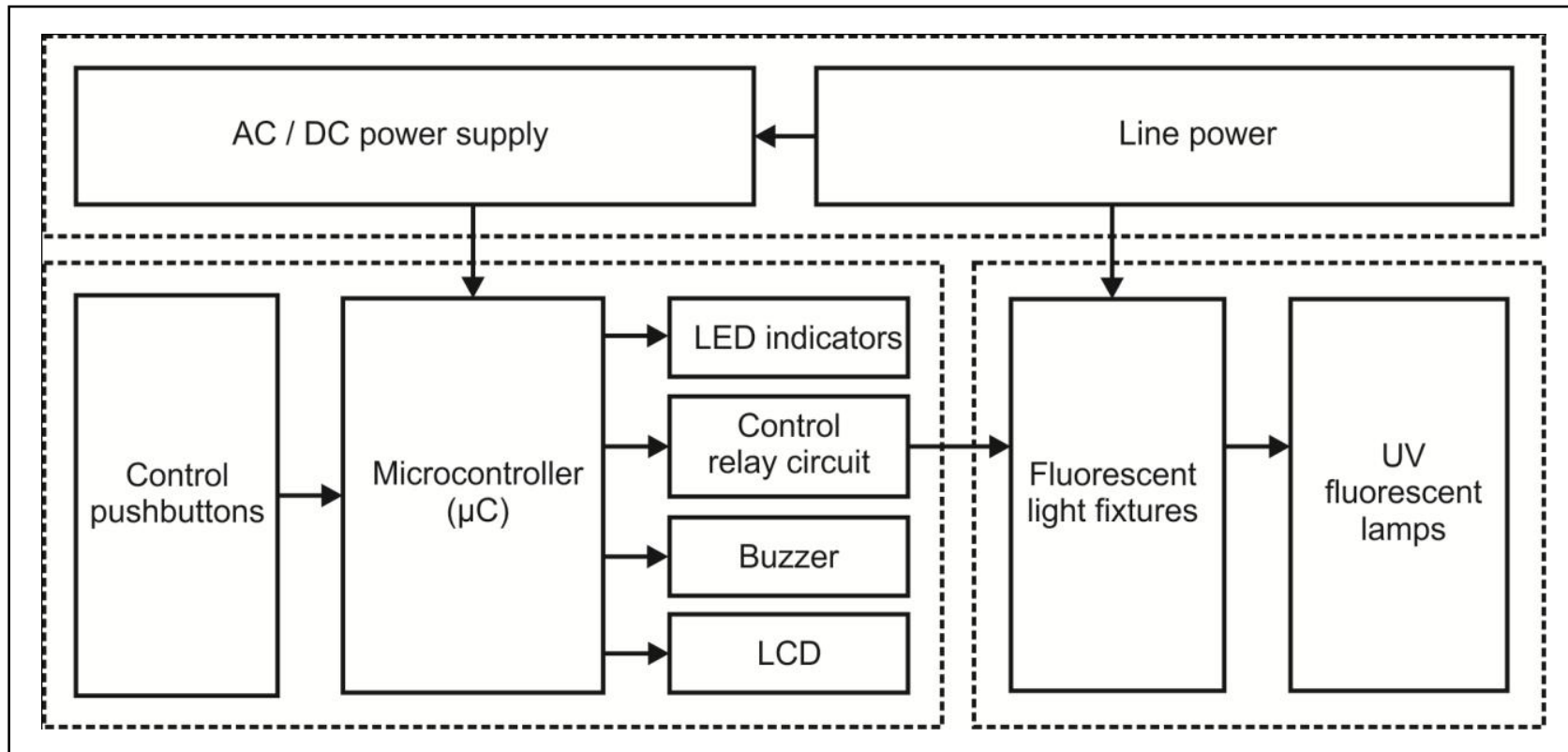

Fig. 6. Block diagram of the implemented UV exposure unit 


\section{TESTING RESULTS}

Generally, exposure time depends on many factors, especially on the light spectrum of the used lamps and the distance between the lamps and a glass. Used UV fluorescent lamps have corresponding light spectrum and the distance between them and the glass is relatively small so it can be assumed that the exposure time will be short. In addition, results also depend on pattern, toner and photoresist, whether presentisized copper clad boards or normal copper clad boards are used. It is very important that the pattern is printed with laser printer. Testing of the implemented solution is carried out with two types of pattern: thermofoil and tracing paper. Results obtained by tracing paper have proved to be better. Also, it is cheaper and has better adhesion properties of the toner so the results obtained by tracing paper are described below.

Test photomask contained a label, board edge, a few thru holes and traces of the following thicknesses in inches: 1/125 (T8), 1/100 (T10), 3/250 (T12), 3/200 (T15), 1/50 (T20), 1/40 (T25) and 3/100 (T30). Just in case, tests were performed in two cycles, first cycle as follows: 8 boards are exposed, each with a different exposure time, starting with a minute up to 8 minutes with a minute step. A brief description of the first cycle is given in the table below.

\begin{tabular}{|c|c|c|}
\hline \multirow{2}{*}{$\begin{array}{c}\text { Board } \\
\text { number }\end{array}$} & \multicolumn{2}{|c|}{ Tests results of the UV exposure unit } \\
\hline & $\begin{array}{l}\text { Exposure time } \\
\text { (minutes) }\end{array}$ & Description \\
\hline 1 & pionome & $\begin{array}{l}\text { Insufficiently illuminated, } \\
\text { photoresist traces remain after } \\
\text { development }\end{array}$ \\
\hline 2 & 2 & Excellent PCB \\
\hline 3 & 3 & $\begin{array}{l}\text { All traces are still complete and } \\
\text { unbroken but there are signs of too } \\
\text { long exposure time }\end{array}$ \\
\hline 4 & 4 & $\begin{array}{l}\text { T8 trace is poorly visible, other } \\
\text { tracks as on the previous } \mathrm{PCB}\end{array}$ \\
\hline 5 & 5 & $\begin{array}{l}\text { T8 trace disappeared, T10 and board } \\
\text { edge are poorly visible, T12 is } \\
\text { broken in several places }\end{array}$ \\
\hline 6 & 6 & $\begin{array}{l}\mathrm{T} 8 \text { and } \mathrm{T} 10 \text { traces and board edge } \\
\text { disappeared, } \mathrm{T} 12 \text { and } \mathrm{T} 15 \text { and label } \\
\text { are poorly visible }\end{array}$ \\
\hline 7 & 7 & $\begin{array}{l}\mathrm{T} 8, \mathrm{~T} 10, \mathrm{~T} 12, \mathrm{~T} 15 \text { traces, board edge } \\
\text { and label disappeared, other lines } \\
\text { and thru-holes are visible in traces }\end{array}$ \\
\hline 8 & 8 & Almost everything disappeared \\
\hline
\end{tabular}

Tab. 1. Results of the first cycle

Second cycle is more detailed and serves only to confirm obtained results. It was performed as follows: 3 boards are exposed, first for a minute and a half, second for 2 minutes and a half and third for 2 minutes and a half. A brief description of the second cycle is given in the table below.

\begin{tabular}{|c|c|l|}
\hline \multirow{2}{*}{$\begin{array}{c}\text { Board } \\
\text { number }\end{array}$} & \multicolumn{2}{|c|}{ Tests results of the UV exposure unit } \\
\cline { 2 - 3 } & $\begin{array}{c}\text { Exposure time } \\
\text { (minutes) }\end{array}$ & Description \\
\hline 1 & $1: 30$ & Insufficiently illuminated \\
\hline 2 & 2 & Very good results \\
\hline 3 & $2: 30$ & A bit too long exposure time \\
\hline
\end{tabular}

Tab. 2. Results of the second cycle

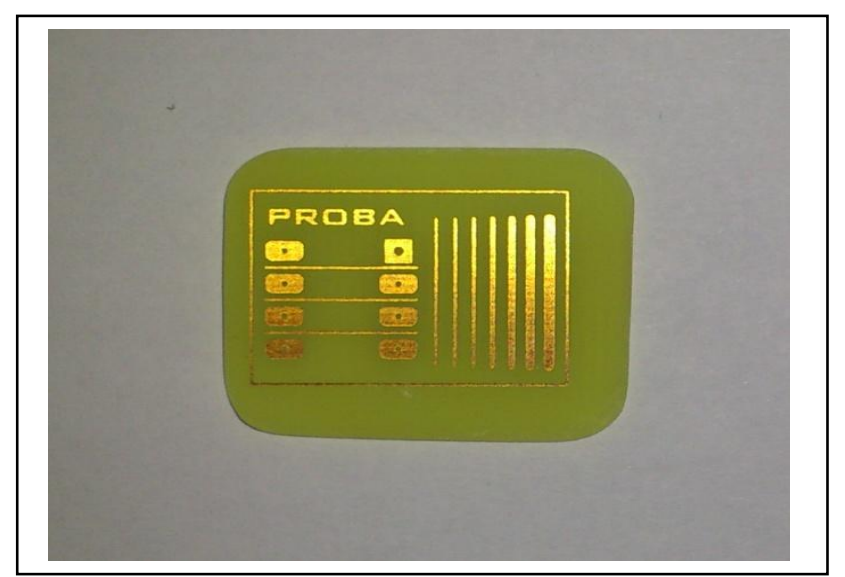

Fig. 7. Photo of the testing PCB

\section{OPEN HARDWARE, OPEN SOFTWARE}

The basic idea is to allow free access to all data related to this project so the user can independently make the device. That includes all the necessary diagrams, blueprints, source codes and other information required for development of such system - open hardware, open software. All data for this project can be found at the following link: www.cset.com.hr/uvexposure

\section{CONCLUSION}

In summary, this project is intended for usage in institutions for technical education which would possibly improve the quality of education of electrical and electronics engineers. A low cost and UV exposure system has been realised and has shown very good results in usage. The total implementation cost is lower than $80 €$, which is a very small amount in comparison with the commercial versions. Future work will be done to develop of UV exposure units with LED panels. Using UV LEDs the cost should be reduced at to half of the current cost.

\section{ACKNOWLEDGEMENTS}

The author wants to express special thanks to the Faculty of Engineering, University of Rijeka and the Croatian Society for Educational Technology for its support in this project.

\section{REFERENCES}

[1] http://en.wikipedia.org/wiki/Photolithography, (2012). Wikipedia, the free encyclopedia, Photolithography, Accessed on: 2012-0705

[2] Jaeger, Richard C. (2002)., Lithography, In: Introduction to Microelectronic Fabrication (2nd ed.), Upper Saddle River: Prentice Hall, ISBN 0-201-44494-1

[3] Low Energy Lighting - How to Save with CFLs (2010)., Available from: http://www.nef.org.uk/energysaving/lowenergylighting.htm, Accessed on: 2012-07-12

[4] http://www.ecat.lighting.philips.com/1/special-lighting/insecttrap/actinic-bl/actinic-bl-tl-tl-d-t5/928001001030_eu/, (2012)., Philips, E-catalog, Accessed on: 2012-06-15

[5] http://www.opple-lighting.com/3-t5-light-fixture-2.html, (2012)., Opple, Products - Fluorescent Light fixtures, Accessed on: 201206-18 